International Scientific Organization

http://iscientific.org/

Chemistry International

www.bosaljournals.com/chemint/

\title{
Leachates and physicochemical characteristics of Rumuodumaya dumpsites, Niger- Delta, Nigeria
}

\author{
Faith Joyce Igbanoi, Ifeanyi Ezekiel Ihunda and Godson Ndubuisi Iwuoha* \\ Department of Pure and Industrial Chemistry, Faculty of Science, University of Port Harcourt \\ *Corresponding author's E. mail: holygodson@yahoo.com
}

\section{A R T I C L E I N F O}

\section{Article type:}

Short Communication

Article history:

Received November 2017

Accepted October 2018

April 2019 Issue

Keywords:

Solid waste

Landfill

Dumpsites

Leachates

Physicochemical parameters

\section{A B S T R A C T}

The physicochemical characteristics and heavy metal levels of leachates at the Rumuodumaya dumpsites and the surface water of its adjacent river was investigated by appropriate field instrument for in situ measurement, standard procedures and AGILENT 55B spectra for the heavy metals. The results from the dumpsites and surface water of the river generally indicate that as of the time of analysis, there is no serious threat to its immediate environment except the nickel concentrations in the dumpsites and surface water of the river, respectively and whose values were beyond the recommended limit of WHO/USEPA $(0.05 \mathrm{mg} / \mathrm{L})$ for safe drinking water. The trend of the results also indicates that the dumpsites are sources of numerous soil and water pollutants capable of depleting oxygen levels in the river and this could pose several and serious health risk to humans and aquatic life. Adequate solid waste disposal technique should be adopted by the appropriate agency to forestall this threat to the Rumuodumaya environment.

(c) 2019 International Scientific Organization: All rights reserved.

Capsule Summary: Physicochemical characteristics and heavy metal load in leachates at the Rumuodumaya dumpsites and the surface water of adjacent river was investigated and results revealed that modern solid waste disposal methods should be enforced to avoid the nickel toxicity and oxygen depletion in the Rumuodumaya River.

Cite This Article As: F. J. Igbanoi, I. E. Ihunda and G. N. Iwuoha. Leachates and physicochemical characteristics of Rumuodumaya dumpsites, Niger-Delta, Nigeria. Chemistry International 5(2) (2019) 126-131.

\section{INTRODUCTION}

The Niger-delta region of Nigeria with its heavy rainfall and improper waste disposal system is a potential source of many forms of leachates which could be linked to the several environmental health concerns in the area. Generally, leachates can be defined as the liquid produced from infiltration or percolation of liquid (mainly rain) through waste material(s) in a dumpsite or landfill (Monroe, 2001; Ludwig et al., 1993; Keenan et al., 1984).

Leachates could vary significantly from one landfill or dumpsite to another and this in turn depends on the hydrogeology and composition of waste material of that site (Ludwig et al., 1993). Depending on the age of the landfill or dumpsite and of position, leachates normally contains dissolved and suspended material (Henry, 1996). The water based leachates are broadly classified into four groups of contaminants namely; dissolved organic matters, inorganic macro component, heavy metals and xenobiotics compound (Aliks, 1992).

The colour of most leachates on formation is mostly blackish but degenerate to yellowish or brownish or orange coloured cloudy liquid with time due to the presence of oxygen and iron salts in solution and in suspension. Physicochemical properties varies from anoxic and 
effervescent black color liquid to aerobic yellowish liquid that teams up with microorganism mainly sphaerotilus natans (Aliks, 1992).

The high level risks from leachates are due to its significant organic and ammonia concentrations. Pathogenic microorganism levels in leachates are also very important. Non-biodegradable toxic substances present in leachates are of great concerns although this varies according to the nature of waste materials. Leachates flowing into aquatic environment could impact severely the bio-diversity, further diminish the population of aquatic species and impact the immediate and distant environment acutely or chemically. (Adepegba, 2012)

The Rumuodumaya dump site is a well-known one in Obio/Akpor local government area in Rivers State with a stream running beside it, as well as a popular open market visibly present in the vicinity. Its high health risk to human and potential to contaminate the stream adjacent to it and the ground water cannot be over emphasized. The dumpsite is home to all sort of waste material that includes; all manner of unused or discarded foodstuff, vegetable, plastics, bones, discarded animal parts, electronic circuits, electronic components, paper materials etc. During flood and heavy rains leachates and run offs from far and near carry pollutants to river and thereby compromising its water quality significantly (Iskandar, 2010; Kahara 2002; Olago and Aketch 2000; Issaias, 2000; Kithaka 2001).

Due to scanty of research in these dumpsites, the aim of this research was to investigate the leachates physicochemical characteristics of the dumpsites and further link it to the quality of the adjacent stream/river, which has not been reported previously. The results will enable us know some of the health concerns associated with the dumpsite and that of adjourning stream.

\section{MATERIAL AND METHODS}

The study area is the Rumuodumaya dumpsite approximately located with the following geographical coordinates of Latitude $4^{0} 45^{\prime} \mathrm{N}$ and longitude $6^{0} 55^{\prime} \mathrm{E}$ in Obio/Akpor local government area of Rivers State, Nigeria. See figure 1 below for map of study area. Leachates samples were collected along the dumpsite axis at different distances from the massive heaps namely 5, 10, 100 (m) at a depth sufficient to bring out the leachates during the rainy season (June, 2017) from randomly selected leachates drains at the sites in well labeled three different clean bottles that were rinsed with the leachates prior to sample collection for determination of the following physiochemical parameters, Chemical oxygen demand (COD), biochemical oxygen demand (BOD5), $\mathrm{pH}$, sulphates and selected heavy metal. Surface water samples were collected from the river sites for similar physiochemical and heavy metal analysis.

The $\mathrm{pH}$ `and electrical conductivity of the leachates and surface water samples were done in-situ with a portable water test kit to obtain accurate results. The $\mathrm{pH}$ of values was obtained by using mettle Toledo portable $\mathrm{pH}$ standard buffers (4.0 and 7.00). The electrical conductivity meter was used to measure the resistance offered by the water samples between two platinized electrodes which has been standardized with $1412 \mu / \mathrm{cm}$ conductance observed with $0.01 \mathrm{M} \mathrm{KCl}$ at a temperature of $25^{\circ} \mathrm{C}$.

The sulphate levels in the leachates and surface water were determined by the turbidimetric method. In this procedure concentration of the turbidity is calculated against known concentrations of $0.0148 \mathrm{~g}$ of anhydrous $\mathrm{Na}_{2} \mathrm{SO}_{4}$ that was diluted to $100 \mathrm{ml}$ with distilled water. Sodium Chloride in hydrochloric acid and glycerol in ethanol solution was added after which $0.3 \mathrm{~g}$ of Barium chloride was used to produce turbidity. The solution was stirred and absorbance values were noted at $420 \mathrm{~nm}$ using Genesis 10UV spectrophotometer. The Iodometric-Azide modification method was determining BOD over a 5 days period while the open reflux method was used for COD determination.

For heavy metal measurements, water samples were prepared by acid digestion followed by filtration through Whatman No.44 filter paper. The filtrate were used to analyze for the various metals using a flame atomic absorption spectrophotometer model (Agilent 55B SPECTRA) which has been standardized with known concentration of the heavy metals solution and applying the suitable hallow cathode lamp and resonance wavelength of each heavy metal.

\section{RESULTS AND DISCUSSION}

Table 1 shows important physiochemical parameters of leachates Samples obtained at sites 1 to 3 at the Rumuodumaya dumpsite while table 2.0 indicates the corresponding values of the parameters at the adjacent river which flows downstream from site 1 to 3

From Table 1, the $\mathrm{pH}$ value of the leachates obtained has highest (6.70) at site 1 and lowest value (5.99) at site 3 . The $\mathrm{pH}$ values at site 2 and 3 are below the acceptable standards range of 6.5-9.5 as stipulated by WHO (2008) and USEPA (2009) for drinking water. The leachate's $\mathrm{pH}$ value 6.70 at site 1 is within the range and it indicates higher ionic levels of bicarbonates-carbonates around site 1 area. This correlates positively with the values of electrical conductivity at the three sites. At site 1 Electrical conductivity is at highest $(1445 \mu \mathrm{s} / \mathrm{cm})$ and drops sharply at sites 2 and 3 with values corresponding to 173.0 $\mu \mathrm{s} / \mathrm{cm}$ and $80.0 \mu \mathrm{s} / \mathrm{cm}$ respectively. However, the electrical conductivity at the three sites is below the USEPA (2009) maximum value of $2500 \mu \mathrm{s} / \mathrm{cm}$. The highest value at site 1 correlates positivity with its higher $\mathrm{pH}$ and BOD values over sites 2 and 3 . The value 6.70 is also an indicating factor of the presences of very significant levels of total dissolved solids over other sites. These observations are in line with the findings of Guptaa 2009; karanth 1987; and Navnect et al 2010. This value of 6.70 also indicates higher concentration of Bicarbonates over carbonates in site 1 . 


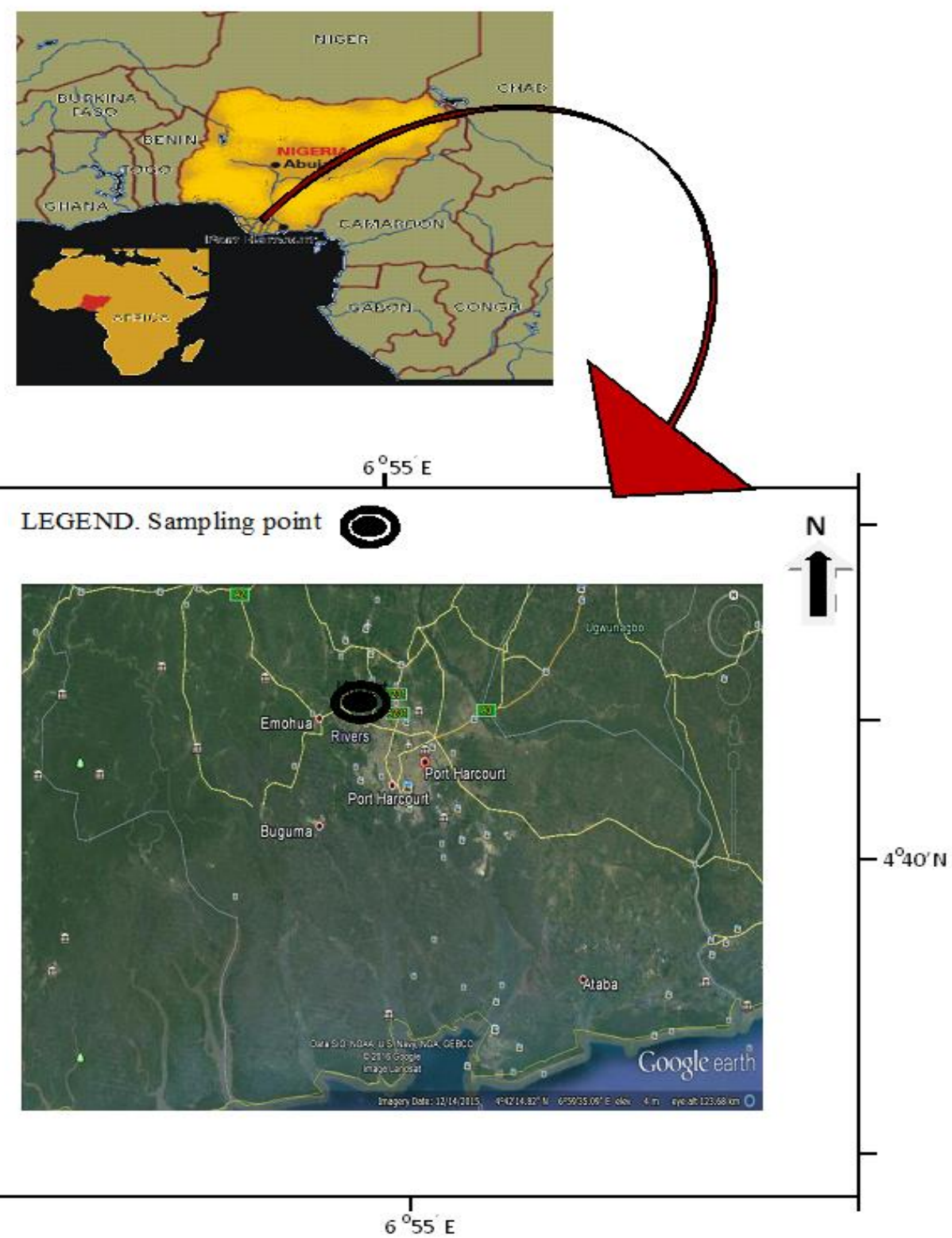

Fig. 1: Map of Port Harcourt, Nigeria indicating sampling point (Rumuodumaya) Google Earth (2018)

The higher levels of $\mathrm{COD}$ and $\mathrm{BOD}_{5}$ values in table 1.0 relative to the maximums for safe drinking water by regulatory body of USEPA standard strongly points to the presence of significant levels of organic material contaminants in the dumpsites, specifically at sites 1 and 2 . The high values indicate that dissolved oxygen is highly depleted. The leachates sulphates values at the dumpsites are relatively uniform with values at $91.81 \mathrm{mg} / \mathrm{L}, 89.04$ $\mathrm{mg} / \mathrm{L}$ and $89.96 \mathrm{mg} / \mathrm{L}$ in site 1,2 and 3 respectively. They are also below WHO/USEPA maximum value $250 \mathrm{mg} / \mathrm{L}$ for safe drinking water.

For the heavy metal concentration $(\mathrm{mg} / \mathrm{L})$ in the leachates obtained in the three sites, only Nickel values are above USEPA maximum level of $0.05 \mathrm{mg} / \mathrm{L}$.
The dumpsite is known for all sort of waste materials that includes; all manner of unused or discarded foodstuff, vegetables, plastics, bones, discarded animal parts, electronic circuits electronic components, paper materials etc. during flooding and heavy rains leachates and runoffs from far and near carry pollutants to the river and thereby compromising its water quality significantly (Achie and Osbanjo 2007; Iskandar, 2010; Kahara 2002; Olago and Aketch 2000; Issaias, 2000; Kithaka 2001).

Chromium, Lead and Copper concentrations are below the detecting limit of the instrument used, indicating that the above three heavy metal concentration is below the respective regulatory standards limit set by USEPA. 
Table 1: Physicochemical properties of leachates samples and standard values

\begin{tabular}{lcccc}
\hline Parameters & Site 1 & Site 2 & Site 3 & Standard values \\
\hline $\mathrm{pH}$ & 6.70 & 6.04 & 5.99 & ${ }^{*}(6.5-9.5)$ \\
Electrical conductivity $(\mu \mathrm{s} / \mathrm{cm})$ & 1445 & 173.0 & 80.0 & ${ }^{*} 2500$ \\
$\mathrm{COD}(\mathrm{mg} / \mathrm{l})$ & 332 & 372 & 308.0 & $(10)^{*} 40$ \\
$\mathrm{BOD}(\mathrm{mg} / \mathrm{l})$ & 7.88 & 6.50 & 5.20 & $(6)^{*} 5$ \\
Sulphate $(\mathrm{mg} / \mathrm{l})$ & 91.83 & 89.04 & 89.96 & ${ }^{*}(250)$ \\
$\mathrm{Ni}(\mathrm{mg} / \mathrm{l})$ & 0.45 & 0.015 & 0.72 & 0.05 \\
$\mathrm{Cr}(\mathrm{mg} / \mathrm{l})$ & $<0.001$ & $<0.001$ & $<0.001$ & 0.05 \\
$\mathrm{~Pb}(\mathrm{mg} / \mathrm{l})$ & $<0.001$ & $<0.001$ & $<0.001$ & 0.05 \\
$\mathrm{Cu}(\mathrm{mg} / \mathrm{l})$ & $<0.001$ & $<0.001$ & $<0.001$ & 1.0 \\
\hline
\end{tabular}

aValues italic = World health organization, WHO, 1985; ( ) = World health organization, 2009 (WHO); * = United states Environment protection agency

Table 2: Physicochemical properties of surface water samples and standard values

\begin{tabular}{lcccc}
\hline Parameters & Site 1 & Site 2 & Site 3 & Standard values \\
\hline $\mathrm{pH}$ & 6.21 & 6.30 & 6.08 & ${ }^{*}(6.5-9.5)$ \\
Electrical conductivity $(\mu \mathrm{s} / \mathrm{cm})$ & 51 & 65 & 55 & ${ }^{*} 2500$ \\
$\mathrm{COD}(\mathrm{mg} / \mathrm{l})$ & 317 & 308 & 212 & $(10)^{*} 40$ \\
$\mathrm{BOD}(\mathrm{mg} / \mathrm{l})$ & 4.03 & 4.22 & 3.90 & $(6)^{*} 5$ \\
$\mathrm{Sulphate}(\mathrm{mg} / \mathrm{l})$ & 91.13 & 90.75 & 87.33 & ${ }^{*}(250)$ \\
$\mathrm{Ni}(\mathrm{mg} / \mathrm{l})$ & 0.26 & 0.33 & 0.14 & 0.05 \\
$\mathrm{Cr}(\mathrm{mg} / \mathrm{l})$ & $<0.001$ & $<0.001$ & $<0.001$ & 0.05 \\
$\mathrm{~Pb}(\mathrm{mg} / \mathrm{l})$ & $<0.001$ & $<0.001$ & $<0.001$ & 0.05 \\
$\mathrm{Cu}(\mathrm{mg} / \mathrm{l})$ & $<0.001$ & $<0.001$ & $<0.001$ & 1.0
\end{tabular}

aValues italic $=$ World health organization, WHO, 1985; ( ) = World health organization, 2009 (WHO); * = United states Environment protection agency

Site 3 recorded the highest levels of nickel $(0.72 \mathrm{mg} / \mathrm{L})$ followed by site $1(0.45 \mathrm{mg} / \mathrm{L})$ and site 2 having the least value in the leachates sample.

For Table 2, we have similar undetected trend of Chromium, Lead and Copper concentrations in the rivers at the three sites however, Nickel was detected and above USEPA value of $0.05 \mathrm{mg} / \mathrm{L}$ in the three sites with values of $0.26 \mathrm{mg} / \mathrm{L}, 0.33 \mathrm{mg} / \mathrm{L}$ and $0.14 \mathrm{mg} / \mathrm{L}$ at sites 1,2 and 3 respectively. The comparisons of Nickel levels in comparison with standard in leachates and surface water from the river is shown in Table 1-2. A similar trend of concentration of sulphate in the leachates versus surface water sample was observed in comparison to standard values. Sulphate values was higher at site 2 just as nickel values was higher at site 2 unlike its levels in site 1 and 3 for both leachates and surface water samples, however at all sites in the river the sulphate concentration are safely below regulatory limit for drinking water. It is possible that higher levels of sulphate and nickel in the surface water at site 2 over their corresponding values in the leachates samples from adjoining dumpsites at site 2 could be as a result of dispersion from upstream from site 1's higher values.

Tables 1-2 also showed the COD and $\mathrm{BOD}_{5}$ values in leachates and surface water versus standard values. This is not unconnected with the respective high levels of organic contamination and biodegradable solid materials at the dumpsites relative to the surface water. Similar trend was also observed in case of electrical conductivity in leachates and the surface water. The positive correlation of electrical conductivity with $\mathrm{COD}, \mathrm{BOD}_{5}, \mathrm{pH}$ and ionic concentrations of water makes it important parameter for monitoring quality of water. The lower values of COD and $\mathrm{BOD}_{5}$ in the surface water relative to its values in the leachates indicates higher values of dissolved oxygen in the river relative to the leachates samples from the dumpsites. Present findings revealed that the leachates may be potential source of adjacent water sources contamination, also previous findings documented that the leachates are one of the main sources of river water contamination (Ayandiran et al., 2018; Camaño Silvestrini et al., 2019; Deng et al., 2019; Hobson et al., 2018; Kang et al., 2019; Kayembe et al., 2018; Mor et al., 2018; Qu et al., 2019; Rai et al., 2019; Rezapour et al., 2018; Scandelai et al., 2018; Tanikawa et al., 2018; Wu et al., 2018; Xiong et al., 2018; Xu et al., 2018; Yuan et al., 2019; Zhao et al., 2018).

\section{CONCLUSIONS}

From the results obtained and following the above discussions one can see the role of the high degradable solid matter and organic material content of the dumpsites played 
as adsorbent in screening out most of the heavy metals except nickel from the leachates. The electrical conductivity values could be used as a credible indicator for leachates and surface water quality. Suitable measures should be taken by appropriate authorities to check the uncontrolled open dumping of degradable and decomposing solid wastes at Rumuodumaya dumpsites in other to minimize suffocation of aquatic organisms due to serious Oxygen depletion and the impact of nickel toxicity to soil and water as well as associated deleterious effect to humans like acute lung cancer, low sperm count in men, eczema and headache.

\section{REFERENCES}

Adepegba, 0., 2012. Leachate Recirculation Practise and views. Retrieved from https://leachate.co.uk/main/leachate-management/.

Adie, G.U., Osibanjo, O., 2007. The impact of effluent of Bodija abattoir on the physical-chemical parameter of Oshunkaye stream in Ibadan City, Nigeria. African Journal of Biotechnology 6, 1806-1811.

Aliks, K.O., 1992. Environmental Analysis 560, 159-165.

Ayandiran, T.A., Fawole, 0.0., Dahunsi, S.O., 2018. Water quality assessment of bitumen polluted Oluwa River, South-Western Nigeria. Water Resources and Industry $19,13-24$.

Camaño Silvestrini, N.E., Maine, M.A., Hadad, H.R., Nocetti, E., Campagnoli, M.A., 2019. Effect of feeding strategy on the performance of a pilot scale vertical flow wetland for the treatment of landfill leachate. Science of the Total Environment 648, 542-549.

Deng, K., Yang, S., Bi, L., Chang, Y.-P., Su, N., Frings, P., Xie, X., 2019. Small dynamic mountainous rivers in Taiwan exhibit large sedimentary geochemical and provenance heterogeneity over multi-spatial scales. Earth and Planetary Science Letters 505, 96-109.

Gupta, D.P., Sunita, Sahara J.P., 2009. Physiochemical analysis of ground water of selected area of Kaithal India, Researcher 1(2), 1-5.

Henry G., 1996. Solid Waste landfill. Environmental Sciences and Engineering 56, 334-410.

Hobson, A.J., Stewart, D.I., Bray, A.W., Mortimer, R.J.G., Mayes, W.M., Riley, A.L., Rogerson, M., Burke, I.T., 2018. Behaviour and fate of vanadium during the aerobic neutralisation of hyperalkaline slag leachate. Science of the Total Environment 643, 1191-1199.

Iskandar, M.B., 2010. The effectiveness of biofilter as a treatment for domestic wastewater. Faculty of Civil Engineering and Earth Resources, University Malaysia Pahang (Thesis).

Issaias, I., 2000. Environmental impact of urbanisation on water resources; A case study of Nairobi dam. Imperial college of science, technology and medicine (university of london), 100.

Kahara, N.S., 2002. characterizing anthropogenic source of pollution for tropical urban river management. A proposed case study of the Nairobi river basin, 87
Kang, M., Tian, Y., Peng, S., Wang, M., 2019. Effect of dissolved oxygen and nutrient levels on heavy metal contents and fractions in river surface sediments. Science of the Total Environment 648, 861-870.

Karanth, K. R., 1987. Groundwater assessment development and management Tata McGraw Hill publishing company Ltd., New Delhi, 725-726.

Kayembe, J.M., Sivalingam, P., Salgado, C.D., Maliani, J., Ngelinkoto, P., Otamonga, J.-P., Mulaji, C.K., Mubedi, J.I., Poté, J., 2018. Assessment of water quality and time accumulation of heavy metals in the sediments of tropical urban rivers: Case of Bumbu River and Kokolo Canal, Kinshasa City, Democratic Republic of the Congo. Journal of African Earth Sciences 147, 536-543.

Keenan J.D., Steiner, R.L., Fungaroli, A.A., 1984. Landfill leachates treatment. Water Pollution Control Federation 56(1), 27-33.

Kitchaka, K., 2001. Assessment of the river water quality and in respect to pollution, Nairobi basin, Nairobi.

Ludwig, D., Hilborn, R., Walters, C., 1993. Uncertainty, resource exploitation, and conservation: lessons from history. Ecological Applications 3, 548-549.

Monroe, M., 2001. Textbook on landfill leachate treatment: VSEP offers a Revolutionary Solution. Retrieved from www.vsep.com/company/articles/2.html.

Mor, S., Negi, P., Khaiwal, R., 2018. Assessment of groundwater pollution by landfills in India using leachate pollution index and estimation of error. Environmental Nanotechnology, Monitoring \& Management 10, 467-476.

Navneet, Kumar, Sinha, D.K., 2010. Drinking water quality management through correlation studies among various physicochemical parameters; A case study, International Journal of Environmental Science 1(2), 253-259.

Olago, O., Aketch, A., 2000. Pollution assessment in river basin pollution assessment report of the Nairobi river basin; Africa Water Network, 106.

Patil, P. N., Sawant, D.V., Deshmukh, R. N., 2012. Physicochemical parameters for testing of water-A review. International Journal of Environmental Sciences 3(3)1194-1207.

Qu, B., Zhang, Y., Kang, S., Sillanpää, M., 2019. Water quality in the Tibetan Plateau: Major ions and trace elements in rivers of the "Water Tower of Asia". Science of the Total Environment 649, 571-581.

Rai, N., Sjöberg, V., Forsberg, G., Karlsson, S., Olsson, P.-E., Jass, J., 2019. Metal contaminated soil leachates from an art glass factory elicit stress response, alter fatty acid metabolism and reduce lifespan in Caenorhabditis elegans. Science of the Total Environment 651, 22182227.

Rezapour, S., Samadi, A., Kalavrouziotis, I.K., Ghaemian, N., 2018. Impact of the uncontrolled leakage of leachate from a municipal solid waste landfill on soil in a cultivated-calcareous environment. Waste Management 82, 51-61.

Scandelai, A.P.J., Cardozo Filho, L., Martins, D.C.C., Freitas, T.K.F.d.S., Garcia, J.C., Tavares, C.R.G., 2018. Combined 
processes of ozonation and supercritical water oxidation for landfill leachate degradation. Waste Management 77, 466-476.

Tanikawa, T., Fujii, S., Sun, L., Hirano, Y., Matsuda, Y., Miyatani, K., Doi, R., Mizoguchi, T., Maie, N., 2018. Leachate from fine root litter is more acidic than leaf litter leachate: A 2.5-year laboratory incubation. Science of the Total Environment 645, 179-191.

United States environmental protection agency. 2009. 816-F09-004.

World Health Organisation (WHO), Geneva, 1985. Guidelines for drinking water quality Volume 1, Recommdation, 130.

World Health Organisation (WHO), Geneva, 2008. Guideline for drinking-water quality (electronic resource), $3^{\text {rd }}$ edition incorporating $1^{\text {st }}$ and $2^{\text {nd }}$ agenda, Volume 1 , Recommdations.

Wu, D., Ma, R., Wei, H., Yang, K., Xie, B., 2018. Simulated discharge of treated landfill leachates reveals a fueled development of antibiotic resistance in receiving tidal river. Environment International 114, 143-151.

Xiong, J., Zheng, Z., Yang, X., He, J., Luo, X., Gao, B., 2018. Mature landfill leachate treatment by the MBBR inoculated with biocarriers from a municipal wastewater treatment plant. Process Safety and Environmental Protection 119, 304-310.

Xu, Y., Xue, X., Dong, L., Nai, C., Liu, Y., Huang, Q., 2018. Longterm dynamics of leachate production, leakage from hazardous waste landfill sites and the impact on groundwater quality and human health. Waste Management 82, 156-166.

Yuan, C., Feng, S., Huo, Z., Ji, Q., 2019. Effects of deficit irrigation with saline water on soil water-salt distribution and water use efficiency of maize for seed production in arid Northwest China. Agricultural Water Management 212, 424-432.

Zhao, R., Feng, J., Yin, X., Liu, J., Fu, W., Berendonk, T.U., Zhang, T., Li, X., Li, B., 2018. Antibiotic resistome in landfill leachate from different cities of China deciphered by metagenomic analysis. Water Research 134, 126-139.

Visit us at: http://bosaljournals.com/chemint/

Submissions are accepted at: editorci@bosaljournals.com 